\title{
Article \\ Clinical Features of Familial Hypercholesterolemia in Children and Adults in EAS-FHSC Regional Center for Rare Diseases in Poland
}

\author{
Joanna Lewek 1,2,* Agnieszka Konopka ${ }^{3}$, Ewa Starostecka ${ }^{3}$, Peter E. Penson ${ }^{4,5}$ D, Marek Maciejewski ${ }^{2}$ \\ and Maciej Banach 1,2,6,*(D)
}

1 Department of Preventive Cardiology and Lipidology, Chair of Nephrology and Hypertension, Medical University of Lodz, 93-338 Lodz, Poland

2 Department of Cardiology and Adult Congenital Heart Diseases, Polish Mother's Memorial Hospital Research Institute (PMMHRI), 93-338 Lodz, Poland; marek.maciejewski@iczmp.edu.pl

3 Regional Rare Disease Centre, Polish Mother's Memorial Hospital Research Institute (PMMHRI), 93-338 Lodz, Poland; agnieszka.konopka@iczmp.edu.pl (A.K.); ewastarostecka@wp.pl (E.S.)

4 School of Pharmacy and Biomolecular Sciences, Liverpool John Moores University, Liverpool L3 3AF, UK; P.Penson@ljmu.ac.uk

5 Liverpool Centre for Cardiovascular Science, Liverpool L7 8TX, UK

6 Cardiovascular Research Centre, University of Zielona Gora, 65-046 Zielona Gora, Poland

* Correspondence: joanna.lewek@umed.lodz.pl (J.L.); maciej.banach@icloud.com (M.B.); Tel.: +48-42-271-15-93 (J.L.); +48-42-271-11-79 (M.B.)

\section{check for} updates

Citation: Lewek, J.; Konopka, A.; Starostecka, E.; Penson, P.E.;

Maciejewski, M.; Banach, M. Clinical Features of Familial

Hypercholesterolemia in Children and Adults in EAS-FHSC Regional Center for Rare Diseases in Poland. J. Clin. Med. 2021, 10, 4302. https:// doi.org/10.3390/jcm10194302

Academic Editors: Emmanuel Androulakis and Emmanuel Andrès

Received: 25 August 2021

Accepted: 17 September 2021

Published: 22 September 2021

Publisher's Note: MDPI stays neutral with regard to jurisdictional claims in published maps and institutional affiliations.

Copyright: (C) 2021 by the authors Licensee MDPI, Basel, Switzerland. This article is an open access article distributed under the terms and conditions of the Creative Commons Attribution (CC BY) license (https:// creativecommons.org/licenses/by/ $4.0 /)$.

\begin{abstract}
Background: Familial hypercholesterolemia (FH) is a genetic autosomal co-dominant metabolic disorder leading to elevated circulating concentrations of low-density lipoprotein cholesterol (LDL-C). Early development of atherosclerotic cardiovascular disease (ASCVD) is common in affected patients. We aimed to evaluate the characteristics and differences in the diagnosis and therapy of FH children and adults. Methods: All consecutive patients who were diagnosed with FH, both phenotypically and with genetic tests, were included in this analysis. All patients are a part of the European Atherosclerosis Society FH-Study Collaboration (FHSC) regional center for rare diseases at the Polish Mother's Memorial Hospital Research Institute (PMMHRI) in Lodz, Poland. Results: Of 103 patients with FH, there were 16 children (15.5\%) at mean age of $9 \pm 3$ years and 87 adults aged $41 \pm 16 ; 59 \%$ were female. Children presented higher mean levels of total cholesterol, LDL-C, and high-density lipoprotein cholesterol (HDL-C) measured at the baseline visit (TC 313 vs. $259 \mathrm{mg} / \mathrm{dL}$ (8.0 vs. $6.6 \mathrm{mmol} / \mathrm{L}), p=0.04$; LDL 247 vs. $192 \mathrm{mg} / \mathrm{dL}$ (6.3 vs. $4.9 \mathrm{mmol} / \mathrm{L}), p=0.02, \mathrm{HDL}$ 53 vs. $48 \mathrm{mg} / \mathrm{dL}$ (1.3 vs. $1.2 \mathrm{mmol} / \mathrm{L}$ ), $p=0.009$ ). Overall, $70 \%$ of adult patients and $56 \%$ of children were prescribed statins (rosuvastatin or atorvastatin) on admission. Combination therapy (dual or triple) was administered for $24 \%$ of adult patients. Furthermore, $13.6 \%$ of adult patients and $19 \%$ of children reported side effects of statin therapy; most of them complained of muscle pain. Only $50 \%$ of adult patients on combination therapy achieved their treatment goals. None of children achieved the treatment goal. Conclusions: Despite a younger age of $\mathrm{FH}$ diagnosis, children presented with higher mean levels of LDL-C than adults. There are still urgent unmet needs concerning effective lipid-lowering therapy in $\mathrm{FH}$ patients, especially the need for greater use of combination therapy, which may allow LDL-C targets to be met in most of the patients.
\end{abstract}

Keywords: familial hypercholesterolemia; registry; lipid-lowering therapy; statins

\section{Introduction}

Familial hypercholesterolemia $(\mathrm{FH})$ is a genetic autosomal co-dominant metabolic disorder caused by defective clearance of low-density lipoprotein cholesterol (LDL-C), leading to lifelong elevations in circulating concentrations [1]. FH occurs in between 1:250 and 1:300 people, meaning that in Europe there are as many as 3 million patients, and over 
64 million worldwide [1-4]. Several tools can be used for FH diagnosis, including: MedPed, Simon Broome, newly proposed The Familial Hypercholesterolemia Case Identification Tool (FAMCAT), and the most widely used Dutch Lipid Clinic Network (DLCN), which assess the clinical probability of a FH diagnosis [2]. Molecular diagnostics testing is recommended (but phenotypic diagnosis is sufficient to start therapy) and allows for genetic testing for mutations in genes responsible for $\mathrm{FH}$ : the most common are in the LDL-C receptor (LDLR), apolipoprotein B (apoB), proprotein convertase subtilisin kexin type 9 (PCSK9), and more rarely the LDLR adaptor protein (LDLRAP1) and apolipoprotein $\mathrm{E}$ (APOE) $[1,5,6]$. In most individuals the mutation is present in one copy of gene with a heterozygous state. Homozygous FH is more severe, with higher levels of LDL-C and poorer prognosis, even at a young age [7]. Homozygous $\mathrm{FH}$ affects a relatively small population of patients, with a prevalence of 1:160,000 to 1:300,000 [7].

It is estimated that FH affects approximately 150,000 people in Poland [8,9]. However, most of these patients are still unaware of their condition, and currently only about $5 \%$ of FH patients in Poland have been diagnosed. Underdiagnosis is a systemic problem in many European countries that needs to be immediately resolved as FH leads to early cardiovascular mortality and morbidity due to the lifetime exposure to high levels of LDL-C $[6,10,11]$. Early development of atherosclerotic cardiovascular disease (ASCVD) is common in FH patients $[6,10,11]$. However, prospective studies show that other risk factors such as hypertension, diabetes, and smoking are also of utmost importance [6]. It has been shown that, even in patients with the comparable level of LDL-C and the same genetic mutation, the risk of adverse events may significantly differ $[6,12]$. Nevertheless, the overall cardiovascular risk in patients with $\mathrm{FH}$ is high, even when there are no other risk factors. Risk in these individuals is classified as high to very high according to European Society of Cardiology/European Atherosclerosis Society (ESC/EAS) guidelines [13], and to extremely high according to recent statements made by the International Lipid Expert Panel (ILEP) [14] and the joint recommendations of Polish Lipid Association and Polish Society of Laboratory Diagnostics [15]. Therefore, increased awareness of FH is very important.

We aimed to evaluate the clinical features of $\mathrm{FH}$ in children and adults based on the data from the PMMHRI Regional Center of Rare Diseases (RCRD) to see the detailed patient's characteristics, including baseline lipid profile and the time of diagnosis, as well as therapy effectiveness and safety. The novelty of this paper is the common analysis of the population including patients at different ages, which is missing in the background literature. This is also one the first registries describing Polish FH population, and one of few from the Central and Eastern European (CEE) countries.

\section{Methods}

The registry, which is a monocentric retrospective observational study, was conducted in RCRD at the PMMHRI (the second largest, supra-regional hospital in Poland), which is a part of the lipid clinic network of the European Atherosclerosis Society FH-Study Collaboration (EAS-FHSC; https:/ / findmylipidclinic.com). Patients were referred to the clinic from the whole country with the referrals from general practitioners and specialists from other clinics due to dyslipidemia.

All consecutive patients with $\mathrm{FH}$, both children and adults, were enrolled between December 2018 and December 2020. All patients were clearly informed about the study and informed consent was obtained from all of them. All patients received a consultation with a clinical geneticist and a dietitian and were provided with recommendations regarding cascade screening among family members, and a healthy and balanced diet was promoted. All index cases were included in the study. The children included in the study were index cases as well.

The registry is administered by physicians from RCRD of PMMHRI, who solely performed all diagnostic and treatment decisions. The inclusion criteria for the patients with familial hypercholesterolemia were being phenotypically or genetically diagnosed with $\mathrm{FH}$. The registry was established to investigate the clinical characteristics, management, and 
clinical outcomes data of FH patients. Phenotypic diagnosis was based on the Dutch Lipid Clinic Network criteria (with at least 6 points), which were assessed in all adult patients, and the Simon Broome criteria were assessed in children. Genetic testing was performed with custom panel of 21 genes - the next-generation sequencing (MiniSeq, Illumina, Inc., San Diego, CA, USA), and then the results were analyzed using available databases and predictive programs (sorting intolerant from tolerant (SIFT) and polymorphism phenotyping (PolyPhen)). Confirmation of detected variants was performed with the Sanger sequencing. During the baseline visit, we collected all the data with all the available lipidogram results. We tried to obtain the naïve values of LDL-C, the highest values, and the treated values. All data acquired during the enrollment period were included in the study. Treatment goals were evaluated at the baseline visit, and the decrease of LDL-C and TC was calculated from the naïve values. Data regarding clinical characteristics, such as age, sex, weight, height, body mass index, blood pressure and heart rate, comorbidities, and symptoms, as well as pharmacotherapy, were collected. All source data were revised by investigators. We collected data regarding family history of ASCVD (including coronary syndromes, stroke, transient ischemic attack (TIA), peripheral arterial disease (PAD), and coronary or other arterial revascularization, with presumed atherosclerotic origin). PAD was defined as all arterial diseases excluding aortic and coronary artery diseases [16]. Data on the side effects of statin therapy were collected based on detailed medical history.

\section{Statistical Analysis}

The Shapiro-Wilk test was performed to check normal distribution. Continuous variables were presented as mean \pm standard deviation or median and interquartile range when appropriate, and as proportions in the case of categorical variables. Comparisons between groups were performed using the Student's $t$-test for independent variables, and various nonparametric tests-the Mann-Whitney U test, $\chi^{2}$ test with Yates correction, and Kruskal-Wallis test-as appropriate. For all calculations, $p$ values $<0.05$ were considered statistically significant. Statistical analysis was performed using the STATISTICA v.13 software (TIBCO Software Inc., Palo Alto, CA, USA).

\section{Results}

Of 103 patients with $\mathrm{FH}$, there were 16 children (15.5\%) aged $9 \pm 3$ years and 87 adults (84.5\%) aged $41 \pm 16$ years; $59 \%$ were female. The diagnosis of $\mathrm{FH}$ in adults was late, at the mean age of 41 years, while in children it was 9 years. Among children and adults with FH, the highest ever recorded levels of total cholesterol (TC) and LDL-C were similar (Table 1). However, children presented with higher mean levels of total cholesterol, LDL-C, and high-density lipoprotein cholesterol (HDL-C) measured at the baseline visit (Table 1). Most of the adults were slightly overweight, and most of the children presented with obesity, which is rather unexpected in a 'normal' (non-FH) population. The detailed characteristics of the FH patients are presented in Table 1 . Among adults, chronic coronary syndrome (CCS) was diagnosed in $8 \%$ patients $(n=7)$, from which $5.7 \%(n=5)$ of patients had a history of myocardial infarction (MI) and $6.9 \%(n=6)$ of patients had received coronary revascularization. PAD occurred in $2.3 \%$ of patients $(n=2)$ and cerebrovascular disease had occurred in $2.3 \%$ of patients $(n=2)$. Additionally, $62 \%$ of adult patients were diagnosed as definite $\mathrm{FH}$ according to DLCN criteria and $38 \%$ as probable $\mathrm{FH}$. Among children, $68 \%$ of patients were classified as definite FH according to Simon Broome criteria and $32 \%$ as possible FH.

Of 41 patients with available results of genetic testing, there were 29 patients $(71 \%)$ with a LDLR mutation, 10 patients $(24 \%)$ with an APOB mutation, and 2 patients $(5 \%)$ with mutations for whom we did not have the medical history with appropriate data (patients had other documents that confirmed that they had pathological mutations, but with no information regarding the type of mutation). Two patients with a LDLR mutation also presented with concomitant mutations in the APOB gene; one patient had the PCSK9 gene mutation. No one presented with the homozygous form of FH. We observed significant 
differences in LDL-C and TC measurements at the baseline visit depending on the underlying gene mutation (Figures 1 and 2). Table 2 displays the results of Kruskal-Wallis test clarified by group pairwise comparison presented in Table 3. LDL-C and TC were significantly higher in patients presenting with LDLR mutation rather than APOB mutation. No significant differences were found in the lipidogram between different DLCN categories.

Table 1. Clinical characteristics and laboratory tests in patients with FH.

\begin{tabular}{|c|c|c|c|c|}
\hline & $\begin{array}{c}\text { Children } \\
(n=16)\end{array}$ & $\begin{array}{l}\text { Adults } \\
(n=87)\end{array}$ & $p$ & Total \\
\hline \multicolumn{5}{|c|}{ Clinical characteristics } \\
\hline Age at baseline visit (years) & $9 \pm 3$ & $41 \pm 16$ & $<0.01$ & $39 \pm 18$ \\
\hline Weight $(\mathrm{kg})$ & $37 \pm 17$ & $82 \pm 17$ & $<0.01$ & $73 \pm 25$ \\
\hline Height $(\mathrm{m})$ & $146(124-159)$ & $170(163-176)$ & $<0.01$ & $165(160-175)$ \\
\hline Body mass index $\left(\mathrm{kg} / \mathrm{m}^{2}\right)$ & $25.3 \pm 1.8$ & $28.4 \pm 5.3$ & 0.42 & $28.2 \pm 5.2$ \\
\hline Systolic blood pressure (mmHg) & $112(104-116)$ & $135(120-150)$ & 0.001 & $128(117-147)$ \\
\hline Diastolic blood pressure (mmHg) & $68(65-74)$ & $82(73-92)$ & 0.004 & $77(71-90)$ \\
\hline Heart rate $(\mathrm{bpm})$ & $70(60-71)$ & $75(63-80)$ & 0.16 & $71(60-80)$ \\
\hline \multicolumn{5}{|c|}{ Laboratory test results } \\
\hline Highest TC ever (mg/dL) & $343 \pm 61$ & $333 \pm 91$ & 0.74 & $335 \pm 85$ \\
\hline Highest LDL ever (mg/dL) & $266 \pm 51$ & $235 \pm 69$ & 0.18 & $241 \pm 66$ \\
\hline $\mathrm{TC}(\mathrm{mg} / \mathrm{dL})$ & $313(279-354)$ & $259(213-334)$ & 0.04 & $266(220-336)$ \\
\hline $\mathrm{LDL}(\mathrm{mg} / \mathrm{dL})$ & $247(206-260)$ & $192(144-251)$ & 0.02 & $195(151-257)$ \\
\hline HDL (mg/dL) & $53(46-67)$ & $48(40-58)$ & 0.009 & $48(40-59)$ \\
\hline $\mathrm{TG}(\mathrm{mg} / \mathrm{dL})$ & $84(67-101)$ & $112(83-175)$ & 0.15 & $107(79-162)$ \\
\hline Glucose (mg/dL) & $83(82-88)$ & 93 (86-97) & 0.04 & $90.5(82-96)$ \\
\hline $\operatorname{AspAT}(\mathrm{U} / \mathrm{L})$ & $24(22-29)$ & $24(19-29)$ & 0.69 & $24(19-29)$ \\
\hline $\operatorname{AlAT}(\mathrm{U} / \mathrm{L})$ & $19(15-27)$ & $23(17-33)$ & 0.21 & $22(15-33)$ \\
\hline Creatinine kinase $(\mathrm{U} / \mathrm{L})$ & $114(58-149$ & $76(63-133)$ & 0.54 & $86(62-140)$ \\
\hline $\mathrm{TSH}(\mu \mathrm{LU} / \mathrm{mL})$ & $1.72(1.43-2.1)$ & $1.77(1.38-2.57)$ & 0.89 & $1.73(1.43-2.46)$ \\
\hline \multicolumn{5}{|c|}{ Pharmacotherapy } \\
\hline Statins (\%) & 56 & 70 & & \\
\hline Ezetymibe (\%) & 0 & 29 & & \\
\hline PCSK9 inhibitors (\%) & 0 & 11.5 & & \\
\hline Fibrates $(\%)$ & 0 & 13.7 & & \\
\hline n-3 fatty acids (\%) & 0 & 13.7 & & \\
\hline
\end{tabular}

Abbreviations: TC—-total cholesterol, bpm—beats per minute, LDL-low-density lipoprotein, HDL—high-density lipoprotein, TG—-triglycerides, AspAT—aspartate transaminase, AlAT—alanine transaminase, TSH—thyroidstimulating hormone, PCSK9-proprotein convertase subtilisin kexin type 9.
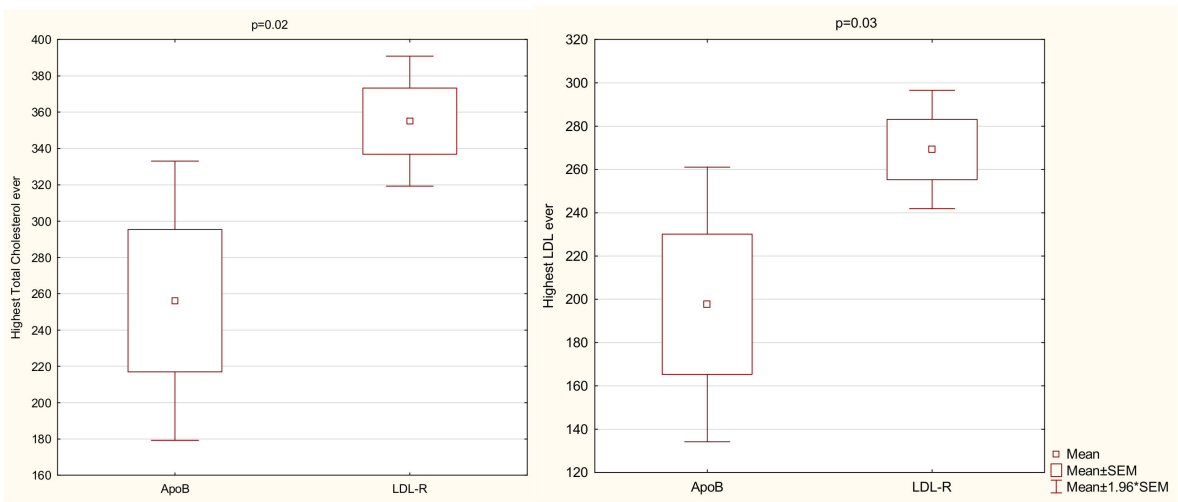

Figure 1. Highest TC and LDL-C ever depending on the underlying gene mutation. Abbreviations: LDL-C-low-density lipoprotein cholesterol, LDLR-low-density lipoprotein receptor, ApoBapolipoprotein B, Min—minimum, Max-maximum, SEM—standard error of the mean. 

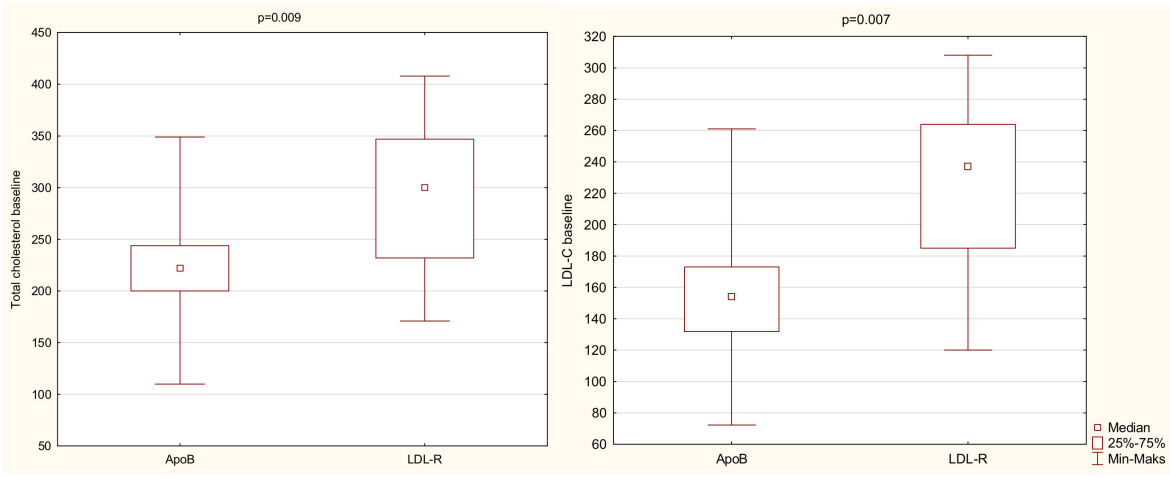

Figure 2. Baseline TC and LDL-C ever depending on the underlying gene mutation. Abbreviations: LDL-C-low-density lipoprotein cholesterol, LDLR-low-density lipoprotein receptor, ApoBapolipoprotein B, Min—minimum, Max-maximum.

Table 2. An association between mutation type and lipidogram.

\begin{tabular}{cccccccccc}
\hline \multicolumn{10}{c}{ Paired Differences } \\
& Mean & SD & Median & $\begin{array}{c}\text { Interquartile } \\
\text { Range }\end{array}$ & Min & Max & $\mathbf{X}^{\mathbf{2}}$ & df & $p$ \\
\hline Highest TC ever & 335 & 85 & 329 & $282-390$ & 142 & 600 & 0.7 & 3 & 0.13 \\
Highest LDL-C ever & 241 & 67 & 243 & $196-293$ & 80 & 400 & 3.5 & 2 & 0.19 \\
TC at baseline & 274 & 71 & 267 & $220-336$ & 110 & 419 & 8.5 & 2 & 0.02 \\
LDL-C at baseline & 200 & 64 & 195 & $151-257$ & 55 & 331 & 3.9 & 2 & 0.02 \\
HDL-C at baseline & 51 & 15 & 48 & $40-59$ & 27 & 102 & 2.5 & 2 & 0.81 \\
TG at baseline & 136 & 112 & 107 & $79-162$ & 33 & 842 & 6.3 & 2 & 0.09
\end{tabular}

Abbreviations: SD—standard deviation, Min—minimum, max-maximum, X2—chi-square, df—degrees of freedom, TC - total cholesterol, LDL-C—-low-density lipoprotein cholesterol, HDL-C—high-density lipoprotein cholesterol, TG-triglycerides.

Table 3. Post hoc pairwise comparison for independent Kruskal-Wallis (KW).

\begin{tabular}{cccc}
\hline & Pairwise Comparison-Gene mutation & Mean Ranks & $p$ of KW \\
\hline \multirow{3}{*}{ LDL-C at baseline } & Lack-LDLR & $21.0 / 20.3$ & 1.0 \\
& LDLR-ApoB & $20.3 / 9.7$ & 0.02 \\
& Lack-ApoB & $21.0 / 9.7$ & 0.44 \\
\hline \multirow{3}{*}{ TC at baseline } & Lack-LDLR & $26.0 / 19.8$ & 1.0 \\
& LDLR-ApoB & $19.8 / 9.7$ & 0.03 \\
& Lack-ApoB & $26.0 / 9.7$ & 0.11 \\
\hline \multirow{2}{*}{ TG at baseline } & Lack-LDLR & $28.5 / 16.1$ & 0.19 \\
& LDLR-ApoB & $16.1 / 12.7$ & 1.0 \\
& Lack-ApoB & $28 . / 12.7$ & 0.08 \\
\hline
\end{tabular}

Abbreviations: KW-Kruskal-Wallis, LDL-C—low-density lipoprotein cholesterol, TC-total cholesterol, TGtriglycerides, LDLR—low-density lipoprotein receptor, ApoB-apolipoprotein B.

Rates of hypertension and diabetes were relatively low in adult patients $(17 \%$ and $11 \%$, respectively). In $17 \%(n=15)$ of patients we observed hypertriglyceridemia defined as $\mathrm{TG} \geq 150 \mathrm{mg} / \mathrm{dL}$ (1.7 mmol/L); most of them presented with mild hypertriglyceridemia, one patient had moderate elevation of TG $(\geq 500 \mathrm{mg} / \mathrm{dL}(5.64 \mathrm{mmol} / \mathrm{L}))$. Among adult patients, two declared that they were current smokers, while six were previous smokers. The prevalence of chronic coronary syndrome, peripheral artery disease, and stroke in family history in the whole population studied was high (in 44 patients- $50 \%, 17$ patients$20 \%$, and 22 patients- $25 \%$, respectively).

Most of the adult patients (70\%) were prescribed statins (rosuvastatin 70\% $(n=42)$ or atorvastatin $27 \%(\mathrm{n}=16))$ at the baseline visit. The mean doses of used statins were $19 \pm 9 \mathrm{mg}$ for atorvastatin and $21 \pm 11 \mathrm{mg}$ for rosuvastatin. Furthermore, 14 patients (13.6\%) declared statin intolerance, and most of them complained of muscle pain; the rest 
(4.6\%) reported hepatic disturbances. Ezetimibe, as a part of combination therapy, was taken by $29 \%(n=25)$ of adult patients. PCSK9 inhibitors were prescribed for $11.5 \%(n=10)$ within the terms of the drug reimbursement scheme, which required the cumulative fulfillment of the following criteria: age 18 or above; diagnosis of $\mathrm{FH}$ with more than 8 points on the DLCN scale; meeting the eligibility criteria for LDL apheresis treatment; and for patients already treated, meeting these criteria at the time of initiation of LDL apheresis treatment. The qualification criteria for LDL apheresis included LDL-C > $160 \mathrm{mg} / \mathrm{dL}$ (4.1 mmol/dL) despite diet and either of the following: (a) intensive treatment with statins at maximum doses, i.e., atorvastatin $80 \mathrm{mg}$ or rosuvastatin $40 \mathrm{mg}$, followed by atorvastatin $40-80 \mathrm{mg}$ or rosuvastatin $20-40 \mathrm{mg}$ in combination with ezetimibe $10 \mathrm{mg}$, used for a total of 6 months, including combination therapy for a minimum one month; OR (b) intensive treatment with statins at maximum tolerated doses, followed by concomitant treatment with ezetimibe $10 \mathrm{mg}$, used for a total of 6 months, including combination therapy for a minimum of 1 month [17]. Fibrates were prescribed in $13.7 \%$ of adult patients $(n=12)$ and $\mathrm{n}-3$ fatty acids in $13.7 \%(\mathrm{n}=12)$. The frequency of statin use in children was lower than in adults $-56 \%(n=9)$ of children were prescribed statins and $19 \%(n=3)$ declared side effects of statin therapy with muscle pain as the side effect of treatment.

Only $50 \%$ of adult patients achieved the treatment goal. Depending on the therapy, the highest efficacy of treatment was obtained in patients on the combination triple lipid lowering therapy (statins, ezetimibe, and PCSK9 inhibitors; $n=9$ ). The mean LDL cholesterol in that group of patients was $59 \pm 33 \mathrm{mg} / \mathrm{dL}$. In patients treated with dual therapy (statins and ezetimibe), the effectiveness of treatment was lower. The effectiveness of the pharmacotherapy is presented in Table 4 . In children treated with statins, the mean decrease of total cholesterol was $41 \%$ (mean absolute reduction by $147 \pm 42 \mathrm{mg} / \mathrm{dL}$ $(3.8 \pm 1.09 \mathrm{mmol} / \mathrm{L}))$ and for LDL cholesterol it was $44 \%$ (mean absolute reduction by $122 \pm 47 \mathrm{mg} / \mathrm{dL}(3.15 \pm 1.22 \mathrm{mmol} / \mathrm{L}))$. None of children achieved the treatment goal.

Table 4. Effectiveness of pharmacotherapy.

\begin{tabular}{|c|c|c|}
\hline & TC & LDL-C \\
\hline & \multicolumn{2}{|c|}{ Triple lipid lowering therapy } \\
\hline Mean decrease (\%) & 58 & 71 \\
\hline \multirow[t]{2}{*}{ Mean absolute reduction } & $\begin{array}{c}200 \pm 121 \mathrm{mg} / \mathrm{dL} \\
(5.17 \pm 3.13 \mathrm{mmol} / \mathrm{L})\end{array}$ & $\begin{array}{c}190 \pm 92 \mathrm{mg} / \mathrm{dL} \\
(4.91 \pm 2.38 \mathrm{mmol} / \mathrm{L})\end{array}$ \\
\hline & \multicolumn{2}{|c|}{ Dual therapy } \\
\hline Mean decrease (\%) & 41 & 38 \\
\hline \multirow[t]{2}{*}{ Mean absolute reduction } & $\begin{array}{c}174 \pm 59 \mathrm{mg} / \mathrm{dL} \\
(4.5 \pm 1.53 \mathrm{mmol} / \mathrm{L})\end{array}$ & $\begin{array}{c}108 \pm 75 \mathrm{mg} / \mathrm{dL} \\
(2.79 \pm 1.94 \mathrm{mmol} / \mathrm{L})\end{array}$ \\
\hline & \multicolumn{2}{|c|}{ Statins } \\
\hline Mean decrease (\%) & 38 & 45 \\
\hline \multirow[t]{2}{*}{ Mean absolute reduction } & $\begin{array}{c}139 \pm 65 \mathrm{mg} / \mathrm{dL} \\
(3.59 \pm 1.68 \mathrm{mmol} / \mathrm{L})\end{array}$ & $\begin{array}{c}119 \pm 57 \mathrm{mg} / \mathrm{dL} \\
(3.08 \pm 1.47 \mathrm{mmol} / \mathrm{L})\end{array}$ \\
\hline & \multicolumn{2}{|c|}{ Ezetimibe } \\
\hline Mean decrease (\%) & 4 & 5 \\
\hline Mean absolute reduction & $\begin{array}{c}14 \mathrm{mg} / \mathrm{dL} \\
(0.36 \mathrm{mmol} / \mathrm{L})\end{array}$ & $\begin{array}{c}14 \mathrm{mg} / \mathrm{dL} \\
(0.36 \mathrm{mmol} / \mathrm{L})\end{array}$ \\
\hline
\end{tabular}

Abbreviations: TC—-total cholesterol, LDL-C—low-density lipoprotein cholesterol.

Adult patients who achieved the treatment goal had a higher DLCN score (mean: 17; SD: $16-19$ vs. $6.5 ; 6-10, p=0.003)$ and glucose measured at baseline $(103 ; 96-112$ vs. $91 ; 86-96, p=0.03$ ) in comparison to patients who did not achieve the treatment goal. Other factors that correlated with the ability to achieve the treatment goal were a premature history of coronary artery disease $(p=0.002)$, history of myocardial infarction $(p=0.02)$, 
history of revascularization $(p=0.04)$, treatment with angiotensin-converting enzyme inhibitors (ACE-I) $(p=0.02)$, and treatment with ezetimibe $(p=0.01)$ and with PCSK9 inhibitors $(p=0.002)$. Treatment with statins (both statin monotherapy or any statin therapy as part of a lipid-lowering regimen) was not linked with the ability to reach treatment goals $(p=0.15)$.

\section{Discussion}

We report the preliminary results of the registry of children and adults with $\mathrm{FH}$ conducted in PMMHRI. We showed that only 50\% of adult patients and none in the group of children were able to achieve the LDL-C target, which was also associated with the lipid-lowering therapy under-prescription and unsuitable doses of statins administrated in the pre-referral period. Based on our analysis, the higher risk of the patients at baseline, the higher chance to be on LDL-C target, especially those being treated with the combination dual and triple therapy, which is still relatively rare. Statin monotherapy does not increase the chances of achieving the goal. Effective treatment of children is still a large challenge, even in specialist centers.

Besides optimal pharmacotherapy, an introduction of healthy diet is highly advised for each patient with FH. At this point, it should be emphasized that we observed that while adults with FH were mostly of normal weight or overweight, and the majority of children were obese. Therefore, the implementation of healthy diet should be initiated as early as possible [18]. In our population, all the patients were advised about how to implement healthy lifestyle including a well-balanced diet. It seems that the help of certified nutritionist/dietitian and the involvement of the whole family is crucial to achieve optimal dietary habits. As part of a balanced diet for $\mathrm{FH}$, patients should consider the inclusion of functional foods such as plant stanols and sterols, which lower LDL cholesterol [19]. Physical activity is also very important. Before implementation of regular exercise to a patient's daily routine, cardiovascular function should be assessed, especially for adult patients with FH $[13,20]$. Moreover, all patients should be warned about potential muscle aches and pains to avoid minor skeletal injuries resulting from exercise being misattributed to statin therapy [21].

Despite increased social awareness of the importance of treating hyperlipidemia, FH is still highly underdiagnosed and undertreated and remains a significant challenge to public policy. We confirmed it in our analysis showing that the age at which FH was diagnosed was relatively high (however, younger in comparison to the other analyses from this region [22]) both in adults (mean age of 41 years) and in children (9 years), what is also raised in all available registries and data from different countries [20]. It is recognized that, if left untreated, FH patients develop ASCVD before the age of 55 in men and 60 in women [23].

The level of highest TC and highest LDL-C observed in our population was similar to the values observed in other published data $[20,24]$. The mean highest recorded TC ever for the individuals in our population was $335 \pm 85 \mathrm{mg} / \mathrm{dL}(8.66 \pm 2.2 \mathrm{mmol} / \mathrm{L})$, while available data show that this is between 310 and $580 \mathrm{mg} / \mathrm{dL}(8.02-15 \mathrm{mmol} / \mathrm{L})$ for untreated patients $[20,24]$.

The prevalence of ASCVD in our population was relatively low (which might have been due to the relatively young age of FH diagnosis-41 years); we observed chronic coronary syndrome in $11.5 \%$ patients, from which $5.7 \%$ patients had a history of myocardial infarction and $7 \%$ patients required revascularization and peripheral artery disease, and cerebrovascular disease was reported in 3\% patients. However, the clinical manifestation of FH usually starts at fourth decade of life [24], which may also explain the relatively low prevalence of ASCD in our population. However, it is worth emphasizing that the prognosis of these patients is poor, as the concept of lifetime LDL exposure dictates that an untreated $\mathrm{FH}$ patient aged 45 years has a similar lifetime exposure to LDL-C as a 70-year-old without FH [25]. 
Therefore, pharmacological treatment should be initiated as early as possible in FH. The recommended LDL-C target for adults with FH at very high CVD risk is $<55 \mathrm{mg} / \mathrm{dL}$ $(<1.4 \mathrm{mmol} / \mathrm{L})$ and a reduction of $>50 \%$ from baseline, both in primary and secondary prevention, and for patients with $\mathrm{FH}$ at high risk, an LDL reduction of $>50 \%$ from baseline and a goal of $70 \mathrm{mg} / \mathrm{dL}(1.8 \mathrm{mmol} / \mathrm{L})$ is recommended (however, it is important to notice that these are rare cases of such patients with $\mathrm{FH}$ and no other risk factors, and/or without subclinical atherosclerosis) [6,13]. However, based on data from available trials [26-28], there are additional suggestions available in the literature both for risk stratification and for the recommended LDL-C targets. These proposals emphasize the fact that patients with FH (those with concomitant ASCVD/acute coronary syndrome) should be considered as having an extremely high CVD risk because of a high cumulative burden of LDL-C. Therefore, a lower LDL-C target $(<40 \mathrm{mg} / \mathrm{dL}(<1 \mathrm{mmol} / \mathrm{L}))$ is warranted $[15,29]$.

The treating of $\mathrm{FH}$ children patients is a great challenge and unmet need. Unfortunately, there are still no clear guidelines about treatment in children. However, the most important issue seems to be an early initiation of therapy to minimize the cumulative burden of LDL-C [18]. The available data suggest that the therapy with statins may be initiated at the age of 6 years, while ezetimibe may be started at the age of 10 years. Other treatment options include bile acid sequestrants [30,31]. In our population, none of the children achieved the treatment goal, which could be a result of overcautious under-dosing in children.

In adults with $\mathrm{FH}$ and concomitant ASCVD, we should start with dual or triple lipid-lowering therapy $[15,29]$, bearing in mind the fact that for most patients at very high or extremely high risk of cardiovascular events, the target can only be achieved with combination therapy [29,32]. In addition to statins and ezetimibe, proprotein convertase subtilisin/kexin type 9 inhibitors (PCSK9 inhibitors) increase the likelihood of achieving treatment targets $[29,32]$. In our population, the percentage of adults receiving triple therapy was low and was limited to patients who had reimbursement by the National Health Fund of Poland [17]. These findings highlight the poor availability of PCSK9 inhibitors, especially the mean reduction of TC and LDL-C in patients treated with combined triple therapy was highest and allowed for the achievement of LDL-C targets in most of the patients. The percentage decrease of LDL-C observed in our population is comparable to the observations made by other researchers [33-36]. The ODYSSEY long-term study evaluated alirocumab vs. placebo in 2341 patients with HeFH with or without ASCVD or with its risk equivalents. PCSK9 inhibitors, added to lipid-lowering treatment in patients who were not adequately controlled, reduced LDL-C by $61.0 \%$ vs. $0.8 \%$ change with placebo (CI: -64.3 to $-59.4 ; p<0.001$ ) [31]. The ODYSSEY ALTERNATIVE study that evaluated 314 patients with $\mathrm{HeFH}$ with a high $\mathrm{CV}$ risk and a history of statin intolerance showed that alirocumab reduced LDL-C by up to $45 \%$ (vs. $14.6 \%$ with ezetimibe) after 24 weeks of treatment $(p<0.0001)$ [32]. Another two studies-ODYSSEY FH I and ODYSSEY FH II-showed a reduction of LDL by $48.8 \%$ for alirocumab compared with an increase of $9.1 \%$ for placebo $(p<0.0001)$ and a $48.7 \%$ reduction compared with a $2.8 \%$ increase with placebo $(p<0.0001)$, respectively [33]. A slightly smaller decrease in LDL-C was observed among 105 patients included in the ODYSSEY HIGH FH trial. Alirocumab has been shown to reduce LDL cholesterol by $46 \%$ (vs. $7 \%$ for placebo with $p<0.001$ ) [36]. The population enrolled in this study is very similar to a group of patients from our registry treated with triple therapy (based on the reimbursement criteria), because inclusion criteria assumed the maximally tolerated dose of statins and LDL cholesterol higher than $160 \mathrm{mg} / \mathrm{dL}$. Despite an absolute mean LDL cholesterol reduction, the goal of therapy was achieved only in $41 \%$ of individuals, which is consistent with the results of our study [36].

In the literature, there are other recently published registries of different populations including the following: Iran Registry of FH (IRFH) [37], Arabian Gulf Region Registry-the Gulf FH Registry [38], Taiwanese Registry [39], Mexico Registry [40], Italian Atherosclerosis Society Network Registry (LIPIGEN) [41], and Spanish Familial Hypercholesterolemia Longitudinal Study (SAFEHEART) [42]. All those registries are national ones with higher 
number of included patients. The IRFH included 263 adult patients with probable or definite FH with lower than in our population LDL cholesterol levels $(142.42 \pm 45.27 \mathrm{mg} / \mathrm{dL}$, $3.68 \pm 1.17 \mathrm{mmol} / \mathrm{L}$ ) and lower number of patients on LLT treatment (54.9\%) [37]. The Gulf FH registry, which was multicenter and multinational study, included 306 adult patients with probable or definite $\mathrm{FH}$. This registry showed a low rate of treated patients, and statin therapy was present in 34\%, ezetimibe in $10 \%$, and PCSK9 inhibitors in $0.4 \%$ of patients. The treatment goals regarding the LDL cholesterol level were achieved only in $12 \%$ of patients [38]. The Mexican FH Registry included 336 adult patients. Genetic testing was performed in $26.9 \%$ of patients. The authors observed higher prevalence of statin therapy (88.1\%) than in our population. Ezetimibe was added to LLT in $35.7 \%$ of patients. However, the treatment goal was achieved only in $13.7 \%$ of patients [40]. All those registries conclude that still most of FH patients are underdiagnosed and undertreated [37,38,40]. The biggest Taiwanese registry was aimed to assess the spectrum of genetic mutations in adult patients with clinically diagnosed FH. Similar to our population, most of the patients presented with a LDLR gene mutation (89\%). The APOB gene mutation was present in $13 \%$ of patients. The PCSK9 mutation was not found in the population studied. The authors identified four novel mutations [39]. It should be emphasized that our registry included both children and adults, which broadens our knowledge about the characteristics of FH in all patients. On the other hand, the interpretation of the obtained results may be more difficult. The Italian registry LIPIGEN, which is an observational, multicenter retrospective and prospective study, included 3480 patients with DLCN score $\geq 6$, among whom $15 \%$ were under 18 years. The authors reported a higher prevalence than in our population of coronary artery disease $(11.3 \%)$, peripheral vascular disease, stroke $(9.6 \%)$, and family history of coronary artery disease (38.8\%) [41]. Another registry, which included children was the SAFEHEART registry, an open, multicenter, Spanish prospective study, which included patients with FH and their relatives older than 15 years. Despite LLT ( $84 \%$ patients received LLT), most of studied population had high levels of LDL-C, not reaching therapeutic goal. Only $3.4 \%$ of patients reached LDL-C $<100 \mathrm{mg} / \mathrm{dL}(2.59 \mathrm{mmol} / \mathrm{L})$ [42].

However, despite many reports already available concerning FH patients in the literature, we believe that the knowledge on FH is still lacking. In most of the countries worldwide, the number of patients diagnosed is usually less than $1-3 \%$. Therefore, each new report is of great importance. It is especially true for CEE countries, including Poland, and based on our best knowledge it is only the second real-life report on $\mathrm{FH}$ population [43] and one of several from this region [22,44]. Moreover, there are large differences in the diagnosis, effectiveness of therapy, and monitoring of $\mathrm{FH}$ patients in different regions of the world, and such papers give possibility to compare these outcomes. Finally, this is one of the few reports that jointly evaluates children and adults with $\mathrm{FH}$, showing some large differences and unmet needs concerning the diagnosis and therapy.

Our analysis has some obvious limitations. This is an analysis of a selected patient population with FH. The main limitation of the study is limited size of the study groups, due to its preliminary report character; however, the registry is ongoing, and these results will be validated in the further analyses. However, despite the small cohort size, the study remains informative. The study group consists of both adults and children, which makes the group heterogeneous but, on the other hand, gives a more complex picture of the $\mathrm{FH}$ patient population. Another limitation is some form of selection bias that perhaps the most serious cases are more likely to be diagnosed in childhood, whereas the less serious cases might escape detection until adulthood.

\section{Conclusions}

In conclusion, despite the younger age of FH diagnosis, children presented with higher mean levels of LDL cholesterol than adults. Therefore, the lifetime exposure to LDL cholesterol starts at a very young age. As a result, there is a need to enable the earlier initiation of therapy and the strict monitoring of the progression of atherosclerosis. Late 
diagnosis of FH in adults, as well as therapy under-prescription and ineffectiveness also represent an unmet clinical need and is likely to be associated with a poorer prognosis.

Author Contributions: J.L.: methodology, formal analysis, investigation, data curation, writingoriginal draft preparation; A.K.: investigation, data curation, E.S.: investigation, data curation, P.E.P.: writing—review and editing, supervision; M.M.: supervision; M.B.: conceptualization, methodology, writing-review and editing, supervision, project administration. All authors have read and agreed to the published version of the manuscript.

Funding: This paper was written independently; no company or institution supported it financially. No professional writer was involved in the preparation of this position paper.

Institutional Review Board Statement: Ethical review and approval were waived for this study; due to the fact this is a retrospective analysis of the consecutive patients with FH treated in our centre.

Informed Consent Statement: Not applicable.

Conflicts of Interest: PEP owns four shares in AstraZeneca PLC and has received honoraria and/or travel reimbursement for events sponsored by AKCEA, Amgen, AMRYT, Link Medical, Mylan, Napp, and Sanofi; MB has received research grant(s)/support from Amgen, Mylan, Sanofi, and Valeant, and has served as a consultant for Akcea, Amgen, Daiichi-Sankyo, Esperion, Freia Pharmaceuticals, Herbapol, Kogen, KRKA, Mylan, Novartis, Novo-Nordisk, Polfarmex, Polpharma, Resverlogix, Sanofi-Regeneron, Servier, Teva, and Zentiva. All other authors have nothing to declare.

\section{References}

1. Vallejo-Vaz, A.J.; Stevens, C.A.; Lyons, A.R.; Dharmayat, K.I.; Freiberger, T.; Hovingh, G.K.; Mata, P.; Raal, F.J.; Santos, R.D.; Soran, H.; et al. Global perspective of familial hypercholesterolaemia: A cross-sectional study from the EAS Familial Hypercholesterolaemia Studies Collaboration (FHSC). Lancet 2021. [CrossRef]

2. Wiegman, A.; Gidding, S.S.; Watts, G.F.; Chapman, M.J.; Ginsberg, H.N.; Cuchel, M.; Ose, L.; Averna, M.; Boileau, C.; Borén, J.; et al. Familial hypercholesterolaemia in children and adolescents: Gaining decades of life by optimizing detection and treatment. Eur. Hear. J. 2015, 36, 2425-2437. [CrossRef] [PubMed]

3. Vallejo-Vaz, A.J.; De Marco, M.; Stevens, C.A.; Akram, A.; Freiberger, T.; Hovingh, G.K.; Kastelein, J.J.; Mata, P.; Raal, F.J.; Santos, R.D.; et al. Overview of the current status of familial hypercholesterolaemia care in over 60 countries-The EAS Familial Hypercholesterolaemia Studies Collaboration (FHSC). Atherosclerosis 2018, 277, 234-255. [CrossRef]

4. Vallejo-Vaz, A.J.; Akram, A.; Seshasai, S.R.K.; Cole, D.; Watts, G.; Hovingh, G.K.; Kastelein, J.J.; Mata, P.; Raal, F.J.; Santos, R.D.; et al. Pooling and expanding registries of familial hypercholesterolaemia to assess gaps in care and improve disease management and outcomes: Rationale and design of the global EAS Familial Hypercholesterolaemia Studies Collaboration. Atheroscler. Suppl. 2016, 22, 1-32. [CrossRef]

5. Di Taranto, M.D.; Giacobbe, C.; Fortunato, G. Familial hypercholesterolemia: A complex genetic disease with variable phenotypes. Eur. J. Med. Genet. 2020, 63, 103831. [CrossRef]

6. Bianconi, V.; Banach, M.; Pirro, M. Why patients with familial hypercholesterolemia are at high cardiovascular risk? Beyond LDL-C levels. Trends Cardiovasc. Med. 2020, 31, 205-215. [CrossRef]

7. Hajighasemi, S.; Gorabi, A.M.; Bianconi, V.; Pirro, M.; Banach, M.; Tafti, H.A.; Reiner, Z.; Sahebkar, A. A review of gene- and cell-based therapies for familial hypercholesterolemia. Pharmacol. Res. 2019, 143, 119-132. [CrossRef]

8. Dyrbuś, K.; Gąsior, M.; Desperak, P.; Osadnik, T.; Nowak, J.; Banach, M. The prevalence and management of familial hypercholesterolemia in patients with acute coronary syndrome in the Polish tertiary centre: Results from the TERCET registry with 19,781 individuals. Atherosclerosis 2019, 288, 33-41. [CrossRef] [PubMed]

9. Banach, M.; Jankowski, P.; Jóźwiak, J.; Cybulska, B.; Windak, A.; Guzik, T.; Mamcarz, A.; Broncel, M.; Tomasik, T. PoLA/CFPiP/PCS Guidelines for the Management of Dyslipidaemias for Family Physicians 2016. Arch. Med. Sci. 2017, 1, 1-45. [CrossRef] [PubMed]

10. Podgórski, M.; Szatko, K.; Stańczyk, M.; Pawlak-Bratkowska, M.; Konopka, A.; Starostecka, E.; Tkaczyk, M.; Góreczny, S.; Rutkowska, L.; Gach, A.; et al. "Apple does not fall far from the tree"-Subclinical atherosclerosis in children with familial hypercholesterolemia. Lipids Health Dis. 2020, 19, 169. [CrossRef] [PubMed]

11. Reiner, Ž.; Simental-Mendía, L.E.; Ruscica, M.; Katsiki, N.; Banach, M.; Al Rasadi, K.; Jamialahmadi, T.; Sahebkar, A. Pulse wave velocity as a measure of arterial stiffness in patients with familial hypercholesterolemia: A systematic review and meta-analysis. Arch. Med. Sci. 2019, 15, 1365-1374. [CrossRef]

12. Santos, R.D. Phenotype vs. genotype in severe familial hypercholesterolemia: What matters most for the clinician? Curr. Opin. Lipidol. 2017, 28, 130-135. [CrossRef] [PubMed] 
13. Mach, F.; Baigent, C.; Catapano, A.L.; Koskinas, K.C.; Casula, M.; Badimon, L.; Chapman, M.J.; De Backer, G.G.; Delgado, V.; Ference, B.A.; et al. 2019 ESC/EAS Guidelines for the management of dyslipidaemias: Lipid modification to reduce cardiovascular risk: The Task Force for the management of dyslipidaemias of the European Society of Cardiology (ESC) and European Atherosclerosis Society (EAS). Eur. Heart J. 2020, 41, 111-188. [CrossRef] [PubMed]

14. Banach, M.; Penson, P.E. What have we learned about lipids and cardiovascular risk from PCSK9 inhibitor outcome trials: ODYSSEY and FOURIER? Cardiovasc. Res. 2019, 115, e26-e31. [CrossRef]

15. Solnica, B.; Sygitowicz, G.; Sitkiewicz, D.; Cybulska, B.; Jóźwiak, J.; Odrowąż-Sypniewska, G.; Banach, M. 2020 Guidelines of the Polish Society of Laboratory Diagnostics (PSLD) and the Polish Lipid Association (PoLA) on laboratory diagnostics of lipid metabolism disorders. Arch. Med. Sci. 2020, 16, 237-252. [CrossRef]

16. Aboyans, V.; Ricco, J.B.; Bartelink, M.L.E.L.; Bjorck, M.; Brodmann, M.; Cohnert, T.; Collet, J.P.; Czerny, M.; De Carlo, M.; Debus, S.; et al. 2017 ESC Guidelines on the diagnosis and treatment of peripheral arterial diseases, in collaboration with the European Society for Vascular Surgery (ESVS): Document covering atherosclerotic disease of extracranial carotid and vertebral, mesenteric, renal, upper and lower extremity arteries. Eur. Heart J. 2018, 39, 763-816. [PubMed]

17. Available online: https://www.gov.pl/web/zdrowie/choroby-nieonkologiczne (accessed on 28 July 2021).

18. Mysliwiec, M.; Walczak, M.; Małecka-Tendera, E.; Dobrzanska, A.; Cybulska, B.; Filipiak, K.; Mazur, A.; Jarosz-Chobot, P.; Szadkowska, A.; Rynkiewicz, A.; et al. Management of familial hypercholesterolemia in children and adolescents. Position paper of the Polish Lipid Expert Forum. J. Clin. Lipidol. 2014, 8, 173-180. [CrossRef]

19. Cicero, A.F.G.; Colletti, A.; Bajraktari, G.; Descamps, O.; Djuric, D.M.; Ezhov, M.; Fras, Z.; Katsiki, N.; Langlois, M.; Latkovskis, G.; et al. Lipid lowering nutraceuticals in clinical practice: Position paper from an International Lipid Expert Panel. Arch. Med. Sci. 2017, 13, 965-1005. [CrossRef]

20. Versmissen, J.; Oosterveer, D.; Yazdanpanah, M.; Defesche, J.C.; Basart, D.C.G.; Liem, A.H.; Heeringa, J.; Witteman, J.C.; Lansberg, P.J.; Kastelein, J.J.P.; et al. Efficacy of statins in familial hypercholesterolaemia: A long term cohort study. BMJ 2008, 337, a2423. [CrossRef]

21. Katsiki, N.; Mikhailidis, D.P.; Bajraktari, G.; Miserez, A.R.; Cicero, A.F.G.; Bruckert, E.; Serban, M.C.; Mirrakhimov, E.; Alnouri, F.; Reiner, Ž.; et al. Statin therapy in athletes and patients performing regular intense exercise-Position paper from the International Lipid Expert Panel (ILEP). Pharmacol. Res. 2020, 155, 104719. [CrossRef]

22. Vrablik, M.; Raslová, K.; Vohnout, B.; Blaha, V.; Satny, M.; Kyselak, O.; Vaclova, M.; Urbanek, R.; Maskova, J.; Soska, V.; et al. Real-life LDL-C treatment goals achievement in patients with heterozygous familial hypercholesterolemia in the Czech Republic and Slovakia: Results of the PLANET registry. Atherosclerosis 2018, 277, 355-361. [CrossRef] [PubMed]

23. Nordestgaard, B.G.; Chapman, M.J.; Humphries, S.E.; Ginsberg, H.N.; Masana, L.; Descamps, O.S.; Wiklund, O.; Hegele, R.A.; Raal, F.J.; Defesche, J.C.; et al. Familial hypercholesterolaemia is underdiagnosed and undertreated in the general population: Guidance for clinicians to prevent coronary heart disease: Consensus Statement of the European Atherosclerosis Society. Eur. Heart J. 2013, 34, 3478-3490. [CrossRef]

24. Familial Hypercholesterolaemia; A Report of a WHO Consultation; WHO: Geneva, Switzerland, 1998.

25. Starr, B.; Hadfield, S.G.; Hutten, B.A.; Lansberg, P.J.; Leren, T.P.; Damgaard, D.; Neil, H.A.W.; Humphries, S.E. Development of sensitive and specific age- and gender-specific low-density lipoprotein cholesterol cutoffs for diagnosis of first-degree relatives with familial hypercholesterolaemia in cascade testing. Clin. Chem. Lab. Med. 2008, 46, 791-803. [CrossRef]

26. Robinson, J.G.; Huijgen, R.; Ray, K.; Phil, M.; Persons, J.; Kastelein, J.J.P.; Pencina, M.J. Determining when to add nonstatin therapy: A quantitative approach. J. Am. Coll. Cardiol. 2016, 68, 2412-2421. [CrossRef] [PubMed]

27. Robinson, J.G.; Jayanna, M.B.; Brown, A.S.; Aspry, K.; Orringer, C.; Gill, E.A.; Goldberg, A.; Jones, L.K.; Maki, K.; Dixon, D.L.; et al. Enhancing the value of PCSK9 monoclonal antibodies by identifying patients most likely to benefit. A consensus statement from the National Lipid Association. J. Clin. Lipidol. 2019, 13, 525-537. [CrossRef] [PubMed]

28. Diaz, R.; Li, Q.H.; Bhatt, D.L.; Bittner, V.A.; Baccara-Dinet, M.T.; Goodman, S.G.; Jukema, J.W.; Kimura, T.; Parkhomenko, A.; Pordy, R.; et al. Intensity of statin treatment after acute coronary syndrome, residual risk, and its modification by alirocumab: Insights from the ODYSSEY OUTCOMES trial. Eur. J. Prev. Cardiol. 2020, 28, 33-43. [CrossRef]

29. Banach, M.; Penson, P.E.; Vrablik, M.; Bunc, M.; Dyrbus, K.; Fedacko, J.; Gaita, D.; Gierlotka, M.; Jarai, Z.; Magda, S.L.; et al. Optimal use of lipid-lowering therapy after acute coronary syndromes: A Position Paper endorsed by the International Lipid Expert Panel (ILEP). Pharmacol. Res. 2021, 166, 105499. [CrossRef]

30. Maliachova, O.; Stabouli, S. Familial Hypercholesterolemia in Children and Adolescents: Diagnosis and Treatment. Curr. Pharm. Des. 2018, 24, 3672-3677. [CrossRef]

31. Goldberg, A.C.; Hopkins, P.N.; Toth, P.P.; Ballantyne, C.M.; Rader, D.J.; Robinson, J.G.; Daniels, S.R.; Gidding, S.S. Screening, diagnosis and management of pediatric and adult patients: Clinical guidance form the National Lipid Association Expert Panel on Familial Hypercholesteroemia. J. Clin. Lipidol. 2011, 5, 133-140. [CrossRef]

32. Gaudet, G.; López-Sendón, J.L.; Averna, M.; Bigot, G.; Banach, M.; Letierce, A.; Loy, M.; Samuel, R.; Manvelian, G.; Batsu, I.; et al. Safety and efficacy of alirocumab in a real-life setting: The ODYSSEY APPRISE study. Eur. J. Prev. Cardiol. 2020, zwaa097. [CrossRef]

33. Robinson, J.G.; Farnier, M.; Krempf, M.; Bergeron, J.; Luc, G.; Averna, M.; Stroes, E.S.; Langslet, G.; Raal, F.J.; El Shahawy, M.; et al. Efficacy and Safety of Alirocumab in Reducing Lipids and Cardiovascular Events. N. Engl. J. Med. 2015, 372, 1489-1499. [CrossRef] [PubMed] 
34. Moriarty, P.M.; Thompson, P.D.; Cannon, C.P.; Guyton, J.R.; Bergeron, J.; Zieve, F.J.; Bruckert, E.; Jacobson, T.; Kopecky, S.L.; Baccara-Dinet, M.T.; et al. Efficacy and safety of alirocumab vs ezetimibe in statin-intolerant patients, with a statin rechallenge arm: The ODYSSEY ALTERNATIVE randomized trial. J. Clin. Lipidol. 2015, 9, 758-769. [CrossRef] [PubMed]

35. Kastelein, J.J.; Ginsberg, H.N.; Langslet, G.; Hovingh, G.K.; Ceska, R.; Dufour, R.; Blom, D.; Civeira, F.; Krempf, M.; Lorenzato, C.; et al. ODYSSEY FH I and FH II: 78 week results with alirocumab treatment in 735 patients with heterozygous familial hypercholesterolaemia. Eur. Heart J. 2015, 36, 2996-3003. [CrossRef]

36. Ginsberg, H.N.; Rader, D.J.; Raal, F.J.; Guyton, J.R.; Baccara-Dinet, M.T.; Lorenzato, C.; Pordy, R.; Stroes, E. Efficacy and Safety of Alirocumab in Patients with Heterozygous Familial Hypercholesterolemia and LDL-C of $160 \mathrm{mg} / \mathrm{dl}$ or Higher. Cardiovasc. Drugs Ther. 2016, 30, 473-483. [CrossRef]

37. Vaseghi, G.; Taheri, M.; Heshmat-Ghahdarijani, K.; Rayati, M.; Zarfeshani, S.; Pourmoghaddas, A.; Khosravi, A.; Zarepour, E.; Keshavarzrad, P.; Arabi, S.; et al. Familial Hypercholesterolemia (FH) in Iran: Findings from the Four-Year FH Registry. J. Lipids 2021, 2021, 9913969. [CrossRef]

38. Alhabib, K.F.; Al-Rasadi, K.; Almigbal, T.H.; Batais, M.A.; Al-Zakwani, I.; Al-Allaf, F.A.; Al-Waili, K.; Zadjali, F.; Alghamdi, M.; Alnouri, F.; et al. Familial Hypercholesterolemia in the Arabian Gulf Region: Clinical results of the Gulf FH Registry. PLoS ONE 2021, 16, e0251560. [CrossRef]

39. Huang, C.C.; Niu, D.M.; Charng, M.J. Genetic Analysis in a Taiwanese Cohort of 750 Index Patients with Clinically Diagnosed Familial Hypercholesterolemia. J. Atheroscler. Thromb. 2021, 62773, Epub ahead of print.

40. Mehta, R.; Martagon, A.J.; Ramirez, G.A.G.; Antonio-Villa, N.E.; Vargas-Vázquez, A.; Elias-Lopez, D.; Gonzalez-Retana, G.; Rodríguez-Encinas, B.; Ceballos-Macías, J.J.; Romero-Zazueta, A.; et al. Familial hypercholesterolemia in Mexico: Initial insights from the national registry. J. Clin. Lipidol. 2020, 15, 124-133. [CrossRef] [PubMed]

41. Averna, M.; Cefalu', A.B.; Casula, M.; Noto, D.; Arca, M.; Bertolini, S.; Calandra, S.; Catapano, A.L.; Tarugi, P.; Pellegatta, F.; et al. Familial hypercholesterolemia: The Italian Atherosclerosis Society Network (LIPIGEN). Atheroscler. Suppl. 2017, $29,11-16$. [CrossRef]

42. Mata, N.; Alonso, R.; Badimón, L.; Padró, T.; Fuentes, F.; Muñiz, O.; Perez-Jiménez, F.; López-Miranda, J.; Díaz, J.L.; Vidal, J.I.; et al. Clinical characteristics and evaluation of LDL-cholesterol treatment of the Spanish Familial Hypercholesterolemia Longitudinal Cohort Study (SAFEHEART). Lipids Health Dis. 2011, 10, 94. [CrossRef]

43. Dyrbuś, K.; Gassior, M.; Desperak, P.; Osadnik, T.; Banach, M. The prevalence and management of familial hypercholesterolemia in patients with acute coronary syndrome in Poland: Results from the TERCET Registry. Eur. Heart J. 2019, 40, P820. [CrossRef]

44. Kutkiene, S.; Petrulioniene, Z.; Laucevicius, A.; Cerkauskiene, R.; Staigyte, J.; Saulyte, A.; Petrulionyte, E.; Gargalskaite, U.; Skiauteryte, E.; Matuzeviciene, G.; et al. Lipid profile evaluation and severe hypercholesterolaemia screening in the middle-aged population according to nationwide primary prevention programme in Lithuania. Atherosclerosis 2018, 277, 267-272. [CrossRef] [PubMed] 